\title{
Sustainability Management of Business Projects in Large Russian Companies
}

\author{
Svetlana Apenko ${ }^{1, *}$, Yulia Fomina ${ }^{1}$ \\ ${ }^{1}$ Dostoevsky Omsk State University, Faculty of Economics, Mira Avenue, 55a, 644077 Omsk, Russia
}

\begin{abstract}
Large companies implement their business activities in the form of projects. The problem of implementing business projects based on the concept of sustainable development is becoming more urgent. The concept assumes management of business projects in such a way that allows a balance to be struck between the economic, social and environmental interests of groups of stakeholders on an institutional basis at the current time and over the long term. However, there are currently no universal and generally accepted developments in sustainability management. This study aims to develop and test a methodology for assessing and managing the sustainability of business projects that includes values, motives, and the level of maturity of sustainability. The novelty and originality of the methodology lies in the fact that it takes into account four sustainability criteria at once - economic, social, environmental and institutional. It allows the user to identify the level of sustainability, both on the basis of individual criteria and an integral indicator. It also corresponds to the current trend of studying the motives and values of implementing the concept of sustainability in projects. The proposed methodology and the test results from 36 large companies in Russia will help business project managers cope with the growing complexity of the social, environmental and economic environments.
\end{abstract}

Keywords: business projects; sustainability assessment; sustainability management

\section{Introduction}

Business projects related to the search for new ideas and the implementation of innovative technologies and products occupy a significant share of the activities of companies. A modern requirement for business projects, as is recognized worldwide, is sustainability, i.e. striking a balance between the economic, social and environmental effects now and over the long term.

This study focuses on the assessment of the sustainability management of business projects in large organizations. Although sustainability management is a new concept for many businesses in Russia, it has recently attracted more attention and is becoming popular. Sustainability management provides companies with the resources to cope with the growing complexity of the social, environmental and economic environments. Sustainability management is particularly relevant for large companies that are involved in large international business projects and programmes and are required to comply with sustainability requirements and report on sustainability. Large companies also use their projects to participate in the life of the regions in which they operate, so the image of business projects being sustainable becomes a significant social and economic factor.

The main and typical problem of the concept of sustainable development is its practical integration in people and processes. [1] It is important that sustainability becomes a core value and core competence of entrepreneurs, rather than a formal policy requirement. For many business projects, it is difficult to achieve a balance between economic, social, environmental and institutional principles. The problem of measuring the sustainability of business activities is also relevant.

The solution to the identified problems should be based on a well-developed theoretical basis. However, an analysis thereof shows that there are many unresolved issues.

\section{Theoretical background}

The sustainability management of business projects is based on the idea of sustainability. Sustainability is broadly defined as the ability of a system or process to sustain itself over a long period of time [2]. In this interpretation, sustainability is embedded in the concept of "sustainable development", proclaimed in the 1987 Brundtland Report as "our common future" and relevant at the current time [3,4]. Sustainable development can be defined as development

\footnotetext{
${ }^{*}$ Corresponding author: apenkosn@yandex.ru
} 
$[5,6]$. The concept of sustainable development is aimed at enabling everyone to lead a decent life and protect the planet from damage $[7,8,9]$

Sustainability management can be defined as "organizational practices that lead to sustainable development" [10]. This practice is aimed at achieving a balance between the environmental, economic and social interests of different groups of stakeholders both in the short and long term [11, 12].

Sustainable development includes three principles: environmental sustainability, economic opportunity and social inclusion [4]. These three principles are also embedded in project management. For example, the Project Management Institute (PMI) defines sustainability as a new management paradigm that helps to cope with the complexity and dynamics of an organization. The principles of sustainable development - including economic, environmental and social; short, medium and long term; local, regional and global; as well as value-oriented ones - can be used in all project management processes, which improves the quality of project results [13].

The fourth principle of sustainable development is institutional. This principle was included by the UN Commission on Sustainable Development in its system of sustainability indicators. It consists of the commitment of a company and its projects to sustainable development through appropriate strategies and institutional framework for sustainability management.

Our research uses all four principles, although the institutional principle is currently poorly researched and belongs to the problem areas in the theoretical foundations of sustainability.

An analysis of existing research in the field of sustainability management allowed us to identify key problem areas, which then helped us formulate research questions.

The first problem is the lack of integration of a sustainable strategy into people's activities and management processes [14]. Business project managers and organizations do not always produce the expected sustainability values [15]. There is a gap between a sustainable strategy and the realization of the benefits thereof [16]. To solve this problem, it is necessary to assess and strengthen the motives for implementing a sustainability strategy in business project activities.

The second problem is the measurement of sustainability, as well as the development of universally applicable sustainability indicators $[17,18]$. The methodological task, which is still under discussion and not solved, is to find indicators of project management sustainability that are reliable and accurate, but at the same time understandable for different target groups [19,20]. Developing universal methods for assessing sustainability would simplify sustainability measurement and reporting for organizations [10]. A particular problem is the inclusion of economic, social, environmental and institutional criteria in the system of indicators [21, 22]. To solve this problem, it is necessary to develop indicators of project sustainability that meet these requirements.

\section{Methodology}

The identified practical problems and gaps in research allowed us to formulate the following research questions: what indicators allow us to comprehensively assess the sustainability management of business projects? What is the current level of sustainability in the business projects of large companies? What are the main motivating factors that encourage managers to implement the principles of sustainable development in management processes in Russia?

The purpose of our research is to develop a methodology for assessing and managing the sustainability of business projects, including values, motives and maturity level, as well as to test this methodology in practice.

The methodology for assessing sustainability is implemented using a new methodology developed by us. It involves assessing the level of maturity of sustainability over three modules. The first module includes questions for assessing the institutional criterion of sustainability management; the second module includes questions on the three dimensions of sustainability - economic, social and environmental; [2, 10, 11, 12, 13, 23] and the third module includes questions related to the motives for and values of sustainable development $[10,16]$. The answers to the questions in each module are subsequently translated into point values. The novelty of our methodology and its difference from existing approaches is that it covers four principles of sustainability at once, thereby enabling users to evaluate the motives and values of sustainable business project management in practice.

To conduct the research, a semi-structured online survey was conducted of project managers in Russian companies. The dataset includes responses from 36 companies from twelve regions in Russia, including the cities of Moscow, Omsk, Yekaterinburg, Arkhangelsk, Chelyabinsk, Krasnoyarsk, Kazan, Kyzyl and Ulan-Ude.

The choice was made to study the business projects of large companies (more than 251 employees), which was reflected in the formulated hypothesis: large companies often implement a sustainability strategy and develop the institutional framework for sustainable business project management practices. The study confirmed this hypothesis. The organizations under study implement their projects in various sectors of the economy and include manufacturing, engineering, gas and chemical companies, as well as service companies involved in banking, IT, etc. 
Eleven organizations implement their projects at the international level, eight at the national level, and seventeen at the regional level. All concern business projects related to generating economic benefits from innovative activities. The survey was conducted from November 2018 to October 2019.

\section{Results and Discussion}

The developed methodology enabled us to establish the level of sustainable business project management in large companies, which was determined as average. More specifically, the quantitative value of the level for all the studied companies was 23.47 points out of a maximum 40 points. To classify the results of the sustainability assessment, the following levels of sustainability management were determined:

$$
\begin{aligned}
& 30.1 \text { - } 40 \text { points - high level; } \\
& 20.1 \text { - } 30 \text { points - average level; } \\
& 10.1 \text { - } 20 \text { points - below average; } \\
& 0-10 \text { points - low level. }
\end{aligned}
$$

The integral indicator was obtained by scoring values in two modules - module 1 institutional and module 2 , which assesses the balance of economic, environmental and social sustainability criteria.

Module 1 questions related to the application of a sustainable development strategy; the time frame of the sustainable development strategy; whether the strategy focuses on the balance between environmental, economic and social interests of different groups of project stakeholders. Module 2 questions dealt with the relationship between the three principles of sustainable development - economic, social and environmental - and their role in the organization's strategy; planning the results and consequences of projects; and the economic, social and environmental goals and effects of projects.

Module 2 consisted of three submodules that were evaluated separately for economic, social and environmental sustainability criteria. The social submodule included issues related to training opportunities for project staff; gender equality; inequality in the distribution of staff income; indicators of social sustainability (human rights, poverty reduction, labour protection, support for trade unions, prevention of corruption and bribery, consumer safety, partnership between management and staff of the organization). The environmental submodule included questions about the internal assessment of the project's environmental impact at the planning stage; transport costs and cooperation with local suppliers; renewable energy; waste management; environmental sustainability indicators (water consumption, carbon dioxide emissions, other harmful gases into the atmosphere, energy consumption, materials and other resources). The economic submodule included issues related to the economic sustainability of projects; indicators for return on investment (ROI), net present value (NPV), cash flow, asset liquidity, market share, new jobs, taxes; economic efficiency of corporate social responsibility; economic efficiency of waste processing.

The maximum possible score for each module and submodule was 10 points:

$$
\begin{aligned}
& 7.6 \text { - } 10 \text { points - high level; } \\
& 5.1-7.5 \text { points - average level; } \\
& 2.6-5.0 \text { points - below average; } \\
& 0-2.5 \text { points - low level. }
\end{aligned}
$$

The following results were obtained:

module 1 (institutional module) - 6.83 points, above-average maturity level;

module 2, submodule A (social module) - 5.21 points, average level;

module 2, submodule B (environmental module) - 4.53 points, average level;

module 2, submodule B (economic module) - 6.83 points, above average level.

The results of the study show that a significant proportion of large companies implement business projects on the basis of a developed institutional framework. First of all, they are implemented within the framework of a sustainable development strategy: 31 companies have a sustainability strategy. For the success of this strategy, management processes have been created, which include: setting and achieving a goal that assumes a balance between all sustainability criteria, managing functional areas (content, timing, risks, quality, personnel, and other project areas), taking into account sustainability criteria. Moreover, companies with a pronounced sustainability strategy have a much higher level of maturity in managing the sustainability of business projects compared to companies that do not have a sustainability strategy (Table 1). This suggests that the presence of an institutional framework is a crucial factor in achieving a high level of maturity in sustainability management. 
Table 1. Maturity level of sustainability management according to the presence of a sustainable development strategy (in points)

\begin{tabular}{|c|c|c|c|c|c|c|}
\hline $\begin{array}{c}\text { Presence of a } \\
\text { sustainable } \\
\text { development strategy }\end{array}$ & $\begin{array}{c}\text { Institutional } \\
\text { module }\end{array}$ & $\begin{array}{c}\text { Social } \\
\text { module }\end{array}$ & $\begin{array}{c}\text { Environmental } \\
\text { module }\end{array}$ & $\begin{array}{c}\text { Economic } \\
\text { module }\end{array}$ & $\begin{array}{c}\text { Integral } \\
\text { indicator of the } \\
\text { level of } \\
\text { maturity }\end{array}$ & $\begin{array}{c}\text { Overall level of } \\
\text { sustainability }\end{array}$ \\
\hline All companies & 683 & 5.31 & 4.53 & 6.81 & 23.47 & Average \\
\hline $\begin{array}{c}\text { Companies with a } \\
\text { sustainability strategy }\end{array}$ & 7.71 & 5.92 & 5.13 & 7.29 & 26.05 & Above average \\
\hline $\begin{array}{c}\text { Companies without a } \\
\text { sustainability strategy }\end{array}$ & 1.35 & 1.55 & 0.8 & 3.8 & 7.5 & Low \\
\hline
\end{tabular}

Differences between groups are statistically significant: F-criterion $=6.225 ; \mathrm{p}=0.000$.

Source: Authors.

The data in Table 1 show a higher level for the institutional and economic modules, which indicates that there is a slight imbalance in the sustainability criteria. This concerns the priority of economic interests over social and environmental indicators for the success of business projects.

A significant result was the conclusion about the impact of the type of business projects implemented on the basis of the sustainability indicators (Table 2). The overall level of sustainability of international projects was above average, whereas for national and regional levels it was only average. At the regional level, the project indicator for environmental sustainability is low. This result is due to the fact that international project managers are forced to comply with sustainability requirements and sustainability reporting, otherwise they acquire a negative reputation in international markets.

Table 2. Maturity level of sustainability management according to the type of project (in points)

\begin{tabular}{|c|c|c|c|c|c|c|}
\hline Type of project & $\begin{array}{c}\text { Institutional } \\
\text { module }\end{array}$ & $\begin{array}{c}\text { Social } \\
\text { module }\end{array}$ & $\begin{array}{c}\text { Environmental } \\
\text { module }\end{array}$ & $\begin{array}{c}\text { Economic } \\
\text { module }\end{array}$ & $\begin{array}{c}\text { Integral indicator } \\
\text { of the level of } \\
\text { maturity }\end{array}$ & $\begin{array}{c}\text { Overall level } \\
\text { of } \\
\text { sustainability }\end{array}$ \\
\hline All projects & 6.83 & 5.31 & 4.53 & 6.81 & 23.47 & Average \\
\hline $\begin{array}{c}\text { International } \\
\text { projects }\end{array}$ & 8.50 & 6.70 & 6.09 & 7.73 & 29.02 & $\begin{array}{c}\text { Above } \\
\text { average }\end{array}$ \\
\hline National projects & 6.97 & 4.38 & 5.13 & 5.94 & 22.41 & Average \\
\hline $\begin{array}{c}\text { Regional } \\
\text { projects }\end{array}$ & 5.68 & 4.85 & 3.24 & 6.62 & 20.38 & Average \\
\hline
\end{tabular}

Differences between groups are statistically significant: F-criterion $=6.232 ; \mathrm{p}=0.000$.

Source: Authors.

Module 3 included questions related to the motives for and values of project sustainability. Respondents chose the motives/values that could be possible reasons for implementing the sustainability management of business projects in large companies. Table 3 shows the distribution of responses. As is evident, the leading motive is related to the public opinion that the organization and its projects are considered sustainable. Other motives are more related to the need to respond to the requirements of sustainable development. The motive for internal changes in culture and thinking focused on sustainability is less marked.

Table 3. Motives for/values of sustainability management

\begin{tabular}{|c|c|c|c|c|}
\hline & Motives for/Value of sustainability management & $\begin{array}{c}\text { Absolutely } \\
\text { agree }\end{array}$ & $\begin{array}{l}\text { Partly } \\
\text { agreed }\end{array}$ & Disagree \\
\hline 1 & The public relations value of being seen as a sustainable organization & 19 & 17 & 0 \\
\hline 2 & The growing cost of energy, materials and waste management & 16 & 13 & 7 \\
\hline 3 & The growing body of environmental liability law and the costs of defence & 17 & 13 & 6 \\
\hline 4 & The desire for a change in the culture and dominant social paradigm & 11 & 17 & 8 \\
\hline 5 & The need to work with foreign partners and adhere to international standards & 14 & 17 & 5 \\
\hline 6 & Digital transformation of the economy and society, the increase in open data access & 17 & 17 & 2 \\
\hline
\end{tabular}

Source: Authors.

The research presented here has therefore made a contribution to the development of the concept of sustainability management for business projects. In particular, the idea of the importance of measuring the three criteria of sustainability - social, economic and environmental was developed $[2,12,13,23]$. The development lies in the proposed method for the quantification of these criteria using a wide range of questions and the combining of the individual estimates into a single integral indicator. In addition, the idea of the importance of taking into account the institutional criterion of sustainability was also developed [10]. The proposed methodology involves evaluating the institutional module, as well as establishing an integral indicator based on this criterion. 
Beyond the above, the research also develops the idea of the importance of evaluating and developing the values and motives that stimulate companies and project managers to implement sustainable management. Thus, based on research by Cohen et al. [10, p. 22], we included questions based on motives in the methodology. This enabled us to study the basic motives, the understanding of which helps to better support the sustainability management of business projects.

\section{Conclusion}

One of the main results of the research presented in this contribution was the development and testing of methods for assessing the sustainability management of business projects in organizations. The advantage of the methodology is that it offers an assessment of four sustainability criteria, the three main dimensions (economic, environmental and social) plus the institutional dimension. The proposed methodology produces both an indicator for the individual criteria and an integral indicator that demonstrates the level of maturity of sustainability management.

Testing the method enabled us to obtain significant results in terms of the understanding and further development of the practice of business project sustainability management in companies. In general, the level of maturity recorded was average. However, those companies that implement a sustainability strategy and form the institutional framework for it, have a significantly higher level of maturity. The level of sustainability is higher in the institutional and economic dimensions than in the social and environmental dimensions. The environmental dimension received the lowest scores. Regional projects of companies have particularly low indicators for environmental sustainability. In other words, an imbalance was recorded in the sustainability criteria, which should be the basis for decision-making in the field of sustainability management regarding the business activities of companies.

Among the most important motives/values was the realization that implementing sustainability management in practice leads to the success of an organization in Russia. Within this context, respondents noted the value of public relations in being seen as a sustainable organization.

This study has its limitations, including the small number of participants. The thirty-six companies studied were enough to test our estimation methodology, but not enough to develop a statistical model. Future research will be based on a larger number of participants from different regions of Russia.

\section{References}

1. P. H. Dos Santos, S. M. Neves, D. O. Sant'Anna, C. H. de Oliveira, H. D. Carvalho, The analytic hierarchy process supporting decision making for sustainable development: An overview of applications. Review. Journal of cleaner production. 212, 119-138 (2019)

2. B. Moldan, A. L. Dahl, Challenges to Sustainability Indicators. Sustainability Indicators: a scientific assessment. SCOPE 67. Washington: ISLAND PRESS, 1-24 (2007)

3. World Commission on Environment and Development (WCED). Our Common Future. Oxford: Oxford University Press (1987)

4. M. Del Baldo, M.-G. Baldarelli, Renewing and improving the business model toward sustainability in theory and practice. International Journal of Corporate Social Responsibility. 2(3) (2017)

5. D. Opresnik, M. Seregni, M. Taisch, The Cornerstone of Sustainability Strategy in Manufacturing Companies. In: B. Grabot, B. Vallespir, S. Gomes, A. Bouras, D. Kiritsis (eds) Advances in Production Management Systems. Innovative and Knowledge-Based Production Management in a Global-Local World. 439, 500-507 (2014)

6. A. Ismail, B. Johnson, Managing Organizational Paradoxes in Social Companies: Case Studies from the MENA Region. Voluntas. 30, 516-534 (2019)

7. A.-L. Müller, R. Pfleger, Business transformation towards sustainability. Business Research. 7, 313-350 (2014)

8. A. Marcon, J. F. de Medeiros, J. L. D. Ribeiro, Innovation and environmentally sustainable economy: Identifying the best practices developed by multinationals in Brazil. Journal of Cleaner Production in September. 160, 83-97 (2017)

9. S. Cohen, W. Eimicke, A. Miller, Sustainability Policy. Hastening the Transition to a Cleaner Economy. Hoboken: J. Wiley \& Sons (2015)

10. J. Carboni, M. González, J. Hodgkinson, PRiSM. Project integrating Sustainable Methods. The GPM® Reference Guide to Sustainability in Project Management. Richmond: GPM Global (2013)

11. G. Silvius, M. Kampinga, S. Paniagua, H. Mooi, Considering sustainability in project management decision making: An investigation using Q-methodology. International Journal of Project Management. 35, 1133-1150 (2017)

12. M. Robertson, Sustainability Principles and Practice. $2^{\text {nd }}$ edition. London: Routledge (2017) 
13. R. Gareis, M. Huemann, A. Martinuzzi, Project Management and Sustainable Development Principles. Project Management Institute (2013)

14. V. L. M. Schropfer, J. Tah, E. Kurul, Mapping the knowledge flow in sustainable construction project teams using social network analysis. Engineering, Construction and Architectural Management. 24(2), 229-259 (2017)

15. H. Kopnina, Sustainability: new strategic thinking for business. Environment Development and Sustainability. 19, 27-43 (2017)

16. K. Kohl, Becoming a Sustainable Organization. A Project and Portfolio Management Approach. $1^{\text {st }}$ ed. New York: Taylor \& Francis (2016)

17. S. Karlsson, A. L. Dahl, et al. Meeting Conceptual Challenges. Sustainability Indicators: a scientific assessment. SCOPE 67. Edited by T. Hák, B. Moldan, A. L. Dahl, Washington: ISLAND PRESS, (2007)

18. M. Pislaru, I. V. Herghiligiu, I .B. Robu, Corporate sustainable performance assessment based on fuzzy logic. Journal of cleaner production. 223, 998-1013 (2019)

19. R. B. Gibson, Sustainability Assessment: Applications and opportunities. London: Routledge (2016)

20. T. Bauler, I. Douglas, et al. Identifying Methodological Challenges. In: T. Hák, B. Moldan, A. L. Dahl, Sustainability Indicators: a scientific assessment. SCOPE 67. Washington: ISLAND PRESS, 49-64 (2007)

21. M. Gerner, Assessing and managing sustainability in international perspective: corporate sustainability across cultures - towards a strategic framework implementation approach. International Journal of Corporate Social Responsibility. 4(5) (2019)

22. C. Malesios, P. K. Dey, F. B. Abdelaziz, Supply chain sustainability performance measurement of small and medium sized companies using structural equation modeling. Annals of Operations Research. 294, 623-653 (2018)

23. R. Maltzman, D. Shirley, Green Project Management. Boca Raton, FL: CRC Press (2010) 